\title{
Experimental Assessment of the Annual Growth Ring's Impact on the Mechanical Behavior of Temperate and Tropical Species
}

\author{
Claude Feldman Pambou Nziengui, ${ }^{\mathrm{a}, \mathrm{b}, *}$ Jonas Turesson, ${ }^{\mathrm{c}}$ Rostand Moutou Pitti, ${ }^{\mathrm{a}, \mathrm{d}}$ and \\ Mats Ekevad ${ }^{\text {c }}$
}

\begin{abstract}
An innovative experimental protocol is presented, linking a nondestructive (on computed tomography scanner) and destructive approach (bending test on electrostatic press). This study aimed to evaluate the annual growth ring's impact on the mechanical behavior of wood. The tests were carried out on temperate specimens (Pseudotsuga menziesii and Abies alba Mill) from the Massif Central Region of France and tropical specimens (Aucoumea klaineana Pierre, Milicia excelsa, and Pterocarpus soyauxii) from Gabon. The connection between the mechanical parameters, taken from these tests and their structural characteristics, are also highlighted. Based on these results, a database was formed of the annual growth ring's impact on the mechanical characteristics of these species. A link was found between the annual growth ring and the mechanical and physical characteristics of the species. The number and width of the earlywood ring and its mechanical properties were also investigated for each type of species. This comparison and the link highlighted was possible due to the study of the impact of dry density's specimens, considered in this work as an adjustment parameter on the study of the mechanical behavior of these species.
\end{abstract}

Keywords: Tropical species; Temperate species; Congo basin forest; Massif central forest; Bending test

Contact information: a: Université Clermont Auvergne, CNRS, Institut Pascal, BP 10448, 63000 ClermontFerrand, France; b: USTM, Ecole Polytechnique de Masuku (EPM), LareVa Bois, BP 901 Franceville Gabon; c: Luleå University of Technology, Division of Wood Science and Engineering, Department of Engineering Sciences and Mathematics, Forskargatan 1, 931 87, Skellefteå, Sweden; d: CENAREST, IRT, BP 14070, Libreville, Gabon; *Corresponding author: pclaudefeldman@gmail.com

\section{INTRODUCTION}

Predicting the behavior of wood under mechanical or environmental stress is essential to improve the design and durability of timber structures (Gérard et al. 2011). This refers to the understanding of the various physical and mechanical characteristics of wood. This understanding is affected by the multitude of climates encountered throughout the world, which attribute to each species endemic characteristics proper to the environment in which the species is found (Manfoumbi Boussougou 2012). One explanation of these intrinsic characteristics could be given by the anatomical structure for each species (Fig. 1).

The microscale structure in wood globally affects its mechanical behavior. This can be investigated due to advancements in theoretical, numerical, and experimental approaches. Gershon et al. (2010) have shown that it is necessary to know the microscale structure of palmetto wood to be able to optimize its fracture toughness. Another work on palmetto wood (Saavedra Flores and Haldar 2016) explains that there are influences of 
several micro-structural features (such as cellulose content and its crystallinity, the microfibril angle, and the cell-wall thickness of micro-fibers) on the Young modulus and density.

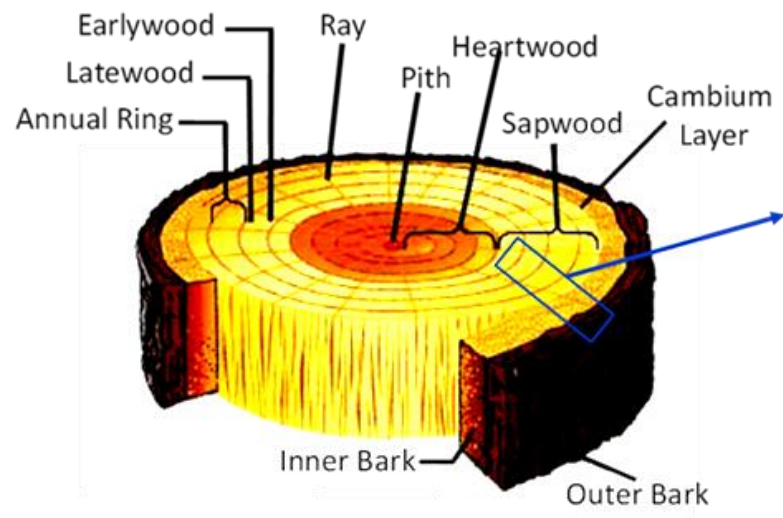

(a)

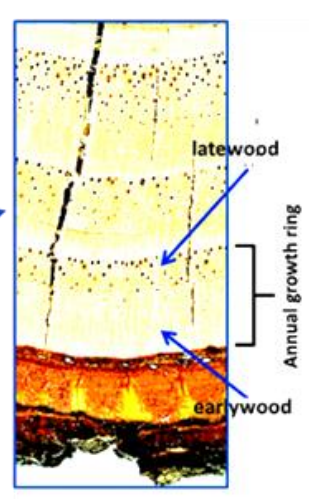

(b)

Fig. 1. (a) Cross-section of a tree trunk and (b) annual growth ring of wood

The growth of annual rings affects the mechanical behavior of wood (Miksic et al. 2013). Wood is a heterogeneous, anisotropic, and hygroscopic natural composite material, with high strength and stiffness relative to its weight (Mishnaevsky and Qing 2008; Bahar et al. 2019). By starting from these hypotheses, Stanzl-Tschegg (2006) noted that the structure of wood is highly optimized for the needs of living trees. This does not mean that wood is optimized for usage in construction, which is the focus of this article. The study by Morales-Conde and Machado (2017) assesses the cross-section for variation of timber bending of modulus of elasticity and brings more information linked to the present work. The authors show, despite the stress waves approach used, a great correlation between the cross-sectional variation and the modulus of elasticity of the wood studied, which roughly fits with the aims of this study. Based on previous studies (Brancheriau et al. 2010; Jaskowska-Lemańska and Wałach 2016; Ramage et al. 2017; Zeller et al. 2017; Abdelmohsen et al. 2019), it is logical to say that the mechanical behavior of wood is based on its micro-structural features, for example content of cellulose, fibril angles, and the annual growth rings.

This work aims at performing an experimental comparative study on five species with different physico-mechanical characteristics. The study is made possible due to a specific experimental approach built by connecting annual growth rings with global mechanical behavior by determining their intrinsic mechanical characteristics. Five species were studied: two European temperate species from the Massif Central in France, Douglas fir (Pseudotsuga Menziesii Franco) and White fir (Abies alba Mill); and three tropical species from Gabon, Okume (Aucoumea klaineana Pierre), Iroko (Milicia excels C.C. Berg) and Padouk (Pterocarpus soyauxii Taub.). The difference between the chosen species is the climate of their habitat. In Gabon, for example, the climate shows a mean annual rainfall of $1900 \mathrm{~mm}$, a mean relative humidity of $85 \%$, and a mean annual temperature of $27{ }^{\circ} \mathrm{C}$ (Medzegue et al. 2007; Pambou Nziengui et al. 2018; Engonga Edzang et al. 2020). This kind of region has two types of seasons: a six months' dry season and a six months' rainy season. During the dry season, almost no rainfall occurs in comparison to the rainy season when most of the rainfall occurs. Thus, the quantity of water 
absorbed by the tree during the rainy season becomes very important for the growth of the tree.

To date, no study has compared tropical species (African tropical region) and temperate species regarding the link between the growth of annual rings and the mechanical properties. The reason for this concern is that the tropical species has a continuous growth of annual rings during the year (Manfoumbi Boussougou 2012; Ramage et al. 2017) and this is not the case for the studied temperate species. Both tropical and temperate species are commonly used in structure for heavy and light frameworks, glulam, paper pulp, fiber panels, in cooperage, packaging, maritime work, and luxury furniture (Adamopoulos et al. 2009; Treml and Jeske 2012; Sopushynskyy et al. 2017). In France there were more than $170 \mathrm{Mm}^{3}$ of white fir and $93 \mathrm{Mm}^{3}$ of Douglas fir in 2009 (Pambou Nziengui et al. 2019). The chosen tropical species are the most widespread species in the tropical forest of Gabon and also among the most exported and used species in the field of timber structures (Odounga et al. 2018).

\section{EXPERIMENTAL}

\section{Wood specimens}

The wood specimens were cuboid shaped with the approximately dimensions of $200 \times 10 \times 10 \mathrm{~mm}^{3}$ (Fig. 2). The fiber direction of the specimens is illustrated in Fig. 2. A total of 125 clear wood specimens was obtained. The specimens of temperate species were taken from collapsed beams used in an earlier study of creep tests (Pambou Nziengui et al. 2019; Tran et al. 2018). The specimens of tropical species were cut from butt logs at an approximate position of one meter above the roots of the standing tree (Odounga et al. 2018). To equalize the moisture content (MC) of the specimens, the specimens were stored in a climate chamber for $48 \mathrm{~h}$. The temperature and the relative humidity in the climate chamber were set to $20{ }^{\circ} \mathrm{C}$ and $64.7 \%$, respectively. Table 1 shows the total number of specimens and the statistical mean of the principal physical characteristics for each group before the experimental campaign.

Table 1. Number of Specimens and Physical Characteristics for Each Tested Species Group with Coefficient of Variation (COV) in Parentheses

\begin{tabular}{|c|c|c|c|c|c|}
\hline & Species & Name & No. & $M C_{\text {mean }}(\%)$ & $\rho_{\text {dry, mean }}\left(\mathrm{kg} / \mathrm{m}^{3}\right)$ \\
\hline \multirow{2}{*}{ Temperate } & Douglas fir & DF & 30 & $9.8(11.1 \%)$ & $563(4.5 \%)$ \\
\cline { 2 - 6 } & White fir & WF & 48 & $9.9(13.6 \%)$ & $447(8.1 \%)$ \\
\hline \multirow{3}{*}{ Tropical } & Iroko & I & 17 & $9.0(17.8 \%)$ & $582(13.8 \%)$ \\
\cline { 2 - 6 } & Padouk & P & 15 & $8.3(13.4 \%)$ & $733(3.0 \%)$ \\
\cline { 2 - 6 } & Okume & O & 15 & $10.3(15.7 \%)$ & $505(4.1 \%)$ \\
\hline
\end{tabular}

No.: number of specimens; $M C_{\text {mean: }}$ mean moisture content; $\rho_{d r y, \text { mean }}$ : mean dry density

To distinguish the earlywood and latewood, which make up the annual growth ring, the specimens were scanned in a computed tomography scanner (CT-scanner). The data from the CT-scanner was visualized and analyzed using the Image $\mathbf{J}$ software (https://imagej.nih.gov/ij/). The CT-scanner used here is capable to reaching around 10 times higher speeds than any other industrial CT-scanner. An image analysis algorithm of this CT-scanner is capable of automatically extracting a large number of relevant parameters (as the presence of knots, fibers direction, internal moisture content, etc.) on 
the specimen studied.

\section{Four-points Flexural Test}

All specimens were loaded in four-point flexural test until failure in an electrostatic press (Fig. 2). The four-point bending test set-up was performed according to the European requirement (EN 408:2010+A1 2012) and as presented by (Manfoumbi Boussougou 2012). The specimens were measured and weighed to determine their physical parameters (Table 1).

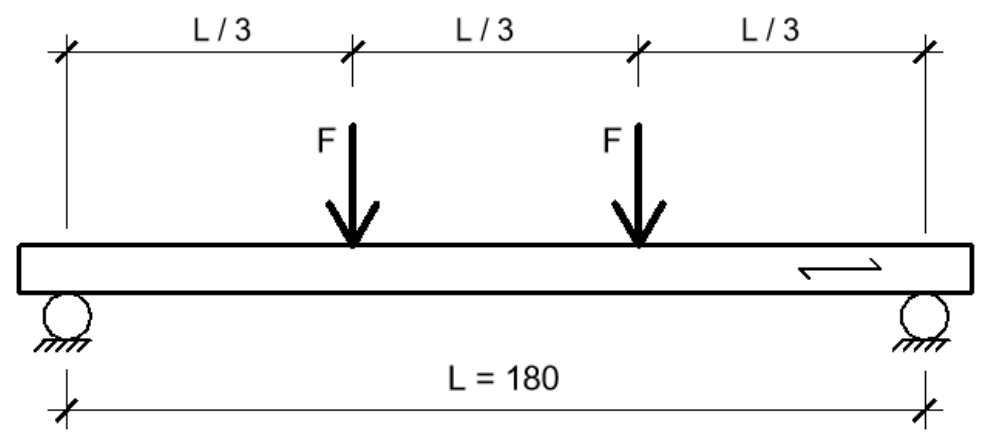

Fig. 2. Four-point flexural test set-up with the fiber direction of the specimen loaded Eq. 1,

The modulus of elasticity (MOE) was calculated for each specimen according to

$$
M O E=\frac{23 L^{3}}{648 I_{z}\left(2 \frac{F_{2}-F_{1}}{W_{2}-W_{1}}-\frac{2 L}{5 G b h}\right)}
$$

where F2-F1 is an increase of force on the regression line and W2-W1 is the increase of the corresponding displacement as described in the European standard requirement (EN 1995-1-1 2004). $L$ represents the distance between the two supports (Fig. 2), $I_{z}$ the moment of inertia, $G$ is the shear modulus, and $b$ and $h$ are the width and height of the specimen, respectively.

Due to lack of data for the tropical species, the influence of $G$ was neglected. The maximum flexural stress was defined to Eq. 2 taken from Timoshenko's beam theory (Timoshenko 1968),

$$
C_{\text {max }}=M_{y} / I_{z}
$$

where $M$ is the flexural moment at the maximum force, $F_{\max }$, during the four-point flexural test, $y$ is the distance from the neutral axis to the area of highest flexural moment and $I_{z}$ the moment of inertia. For this four-point flexural test set-up, $M$ was calculated as presented by Eq. 3,

$$
M=\left(L F_{\max }\right) / 3
$$

To calculate $C_{\max }$, the length $y$ in Eq. 2 can be set equal to $h / 2$ [25]. A comparison between $C_{\max }$ calculated in this study and the maximum flexural failure stress given by the CIRAD wood collection (Gérard et al. 2011), $C_{\text {mcir }}$, was done. The Student's T-test was used to determine the significant difference between means of specimens. The significant level of $\alpha$ was set to 0.05 . 


\section{RESULTS AND DISCUSSION}

\section{Mechanical Characterization of the Specimens in Static Tests}

The mean values of modulus of elasticity $(M O E)$, maximum loading $\left(F_{\max }\right)$, and maximum flexural stress $\left(C_{\max }\right)$ obtained, for each species studied, are presented in Table 2. The $C_{\text {mcir }}$ value is the maximum flexural stress given by the CIRAD wood collection (Gérard et al. 2011). The highest $M O E_{\text {mean }}$ of $15.6 \mathrm{GPa}$ was obtained for DF species. The lowest $M O E_{\text {mean }}$ of $9.2 \mathrm{GPa}$ was calculated for $\mathrm{O}$. The lowest and highest $F_{\text {max }}$, mean was measured for WF and DF, respectively and the specimens with largest variation among the tropical and temperate species was $\mathrm{P}$ and DF, respectively. By taking into account the results of (Gérard et al. 2011) and its dry density (Table 1), $\mathrm{P}$ was expected to have the highest $C_{\max }$ mean among all tested species, but according to Table 2, it had a lower $C_{\max }$ mean but with the highest $C O V$. In general, all tested species (except WF and $\mathrm{P}$ ) had a higher $C_{\max }$, mean than $C_{m c i r}$. These results highlight the intra-extra trees variability, which exists for specimens taken from the same trees.

Table 2. Result from the Four-Point Flexural Test with COV in Parentheses

\begin{tabular}{|l|c|l|l|l|c|}
\hline & Name & $M_{\text {mean }}(\mathrm{GPa})$ & $F_{\text {max, mean }}(\mathrm{N})$ & $C_{\text {max, mean }}(\mathrm{MPa})$ & $C_{\text {mcir }}(\mathrm{MPa})$ \\
\hline \multirow{3}{*}{ Temperate } & $\mathrm{DF}$ & $15.6(10.5 \%)$ & $522(20.7 \%)$ & $102(20.4 \%)$ & 91 \\
\cline { 2 - 6 } & $\mathrm{WF}$ & $10.7(16.4 \%)$ & $383(15.3 \%)$ & $77(16.0 \%)$ & 80 \\
\hline \multirow{4}{*}{ Tropical } & $\mathrm{I}$ & $12.8(18.1 \%)$ & $492(13.7 \%)$ & $94(14.8 \%)$ & 87 \\
\cline { 2 - 6 } & $\mathrm{P}$ & $14.1(13.5 \%)$ & $407(21.6 \%)$ & $83(21.5 \%)$ & 116 \\
\cline { 2 - 6 } & $\mathrm{O}$ & $9.2(9.1 \%)$ & $422(12.7 \%)$ & $82(11.9 \%)$ & 62 \\
\hline
\end{tabular}

Figure 3 shows the evolutions of the $C_{\max }$ versus $M O E$ values for all tested specimens. There was an increasing $C_{\max }$ for a higher $M O E$. This behavior is observable for the both temperate and tropical specimens.
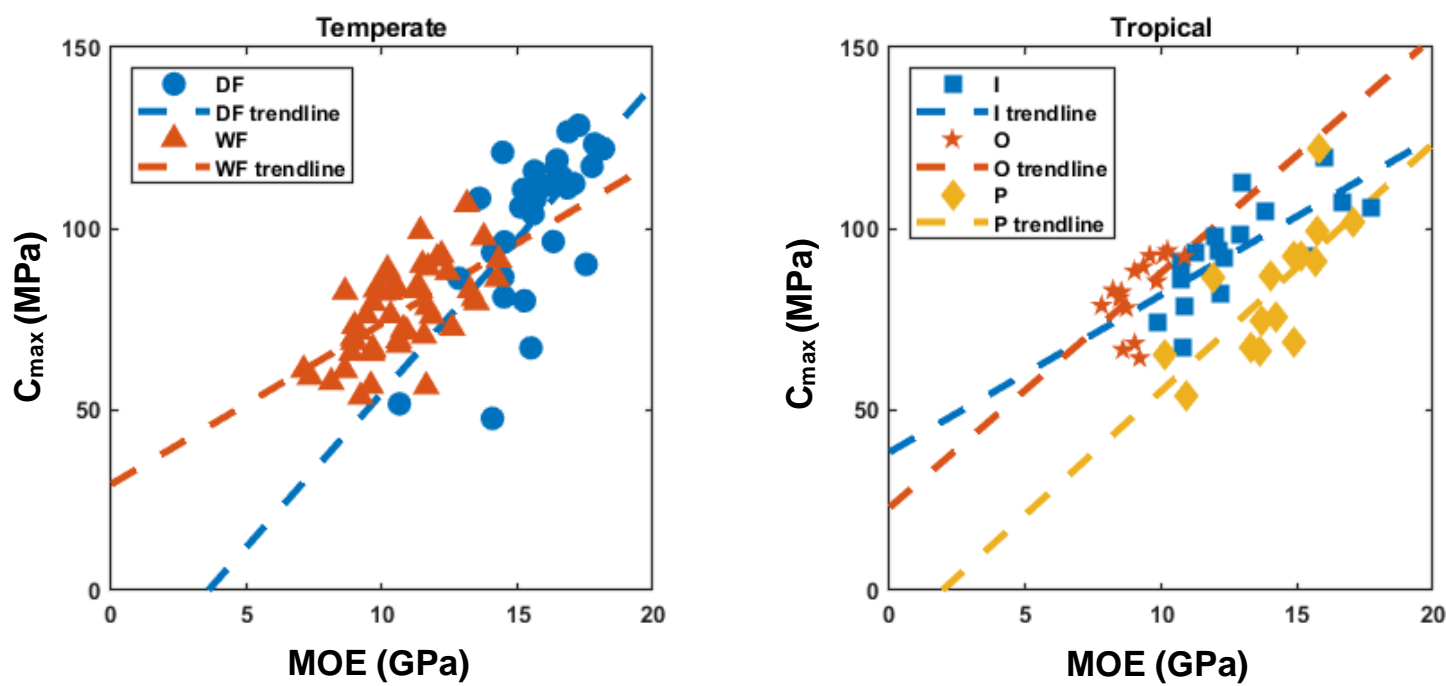

Fig. 3. Modulus of elasticity (MOE) versus maximum flexural stress $\left(\mathrm{C}_{\max }\right)$ for the groups of temperate and tropical specimens 
The difference in $C O V$, which exists for the groups of specimens presented in Table 2, is also visible in Fig. 3 by the highlighting of the dispersion, which seems large for DF (for the temperate specimens) and $\mathrm{P}$ (for tropical specimens). The groups of specimens with lower $\operatorname{COV}(\mathrm{O}$ and $\mathrm{WF})$ showed a non-scattering pattern in Fig. 3 compared to groups of specimens with higher $C O V$. The $\mathrm{R}^{2}$-values for the trendlines were calculated as 0.45 , $0.41,0.53,0.30$, and 0.53 for $\mathrm{DF}, \mathrm{WF}, \mathrm{I}, \mathrm{O}$, and $\mathrm{P}$, respectively.

Figure 4 shows a comparison between the $\rho_{d r y}$ and $C_{\max }$. Due to the low $C O V$ for the $\rho_{d r y}$ of the DF, the DF specimens are non-scattered. The lower values of $C_{\max }$ for some DF specimens occurred due to material variations. The DF specimens with lower $C_{\max }$ were kept in the analysis because they could not be classified as statistical outliers. The results for the temperate specimens were similar for the tropical specimens where the group of specimens with highest $C O V$ could illustrate a trendline with reasonable $\mathrm{R}^{2}$-values. The trendlines in Fig. 4 had an $\mathrm{R}^{2}$-value of 0.40 and 0.35 for WF and I, respectively. The other temperate and tropical specimens resulted in trendlines with low $\mathrm{R}^{2}$-values and are not presented. Iroko (I) was the only tropical group of specimens following a trendline. $\mathrm{O}$ and P did not illustrate a trendline due to the low $C O V$ of $\rho_{d r y}$, which were $4.1 \%$ and $3.0 \%$, respectively. This variation in $\rho_{d r y}$ was too low compared to the $C O V$ of $\rho_{d r y}$ for I and WF, which were $13.8 \%$ and $8.1 \%$, respectively. This statistical study done on the intrinsic mechanical characteristics of the specimens from temperate and tropical species, gives interesting information to build a database of the mechanical properties of the species studied. This database will be important for the next sections of this work.
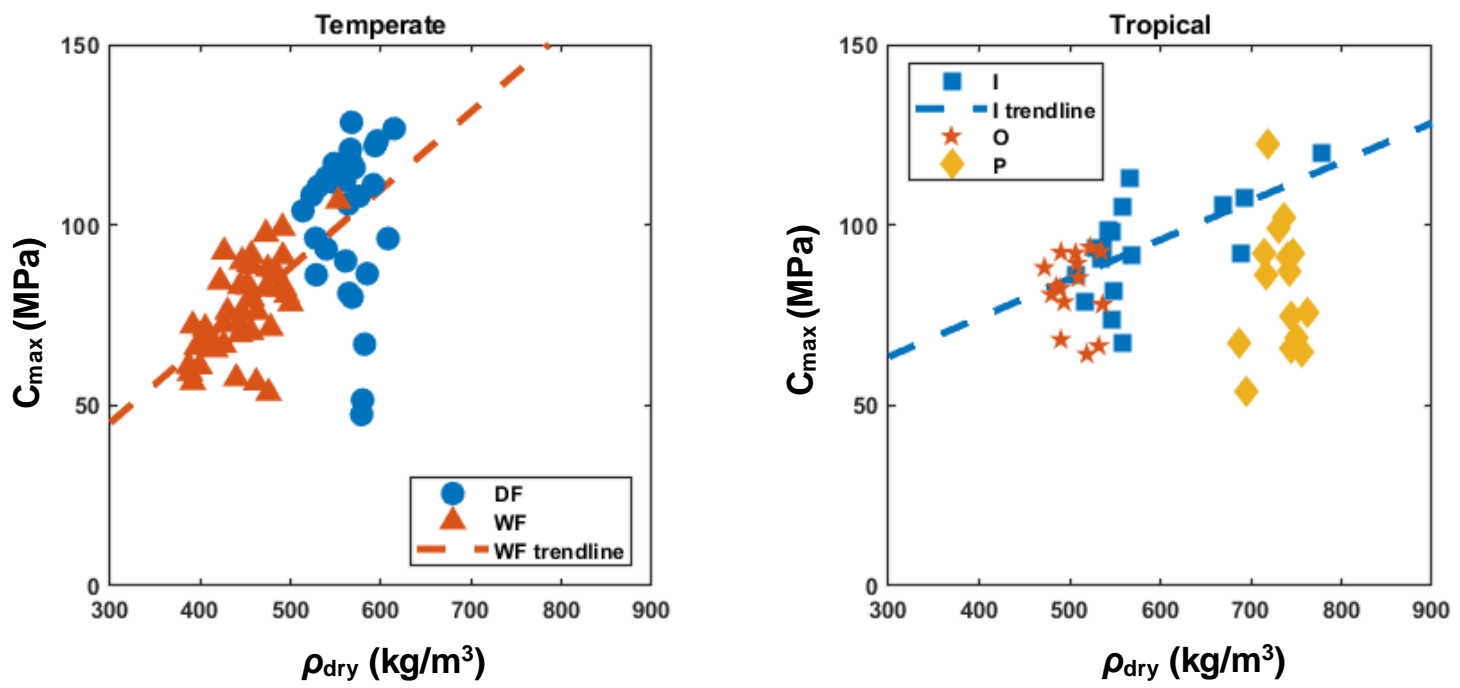

Fig. 4. Dry density $\left(\rho_{d r y}\right)$ versus maximum flexural stress $\left(C_{\max }\right)$ for the groups of temperate and tropical specimens

\section{Cross-section Characterization of the Specimens}

The CT scans of specimen's cross-sections are presented in Fig. 5. The earlywood and latewood, which make up the annual growth rings, are illustrated with white and black color, respectively. The distinction between earlywood and latewood is easily observable for the temperate specimens (Fig. 5, DF and WF species), but on the cross sections of the tropical specimens, the distinction of annual growth ring is almost impossible to see (Fig. 5; O, I and $\mathrm{P}$ species). These observations are in accordance with the literature (EN 408:2010+A1 2012; Sopushynskyy et al. 2017), which shows that the distinction between earlywood and latewood is therefore not obvious in tropical species. The main explanation 
of the non-perception of this difference, for the tropical specimens, could be given by the harsh climate met in the region of their growth and the fact that the tropical species has a continuous growth of the annual rings during the year (Manfoumbi Boussougou 2012; Ramage et al. 2017). Specifically, for the P specimens the distinction between the lines of latewood and earlywood seems very difficult to observe, which is the same case for $\mathrm{O}$ and I. In the specimens O2, O12, I3, and I5 (Fig. 5), there is little distinction observable between the latewood and earlywood of these tropical species. The density difference through the specimen could explain the difference. By taking into account this result, globally for the tropical species, the scanning of their cross-section does not make it possible to distinguish the line between earlywood and latewood.

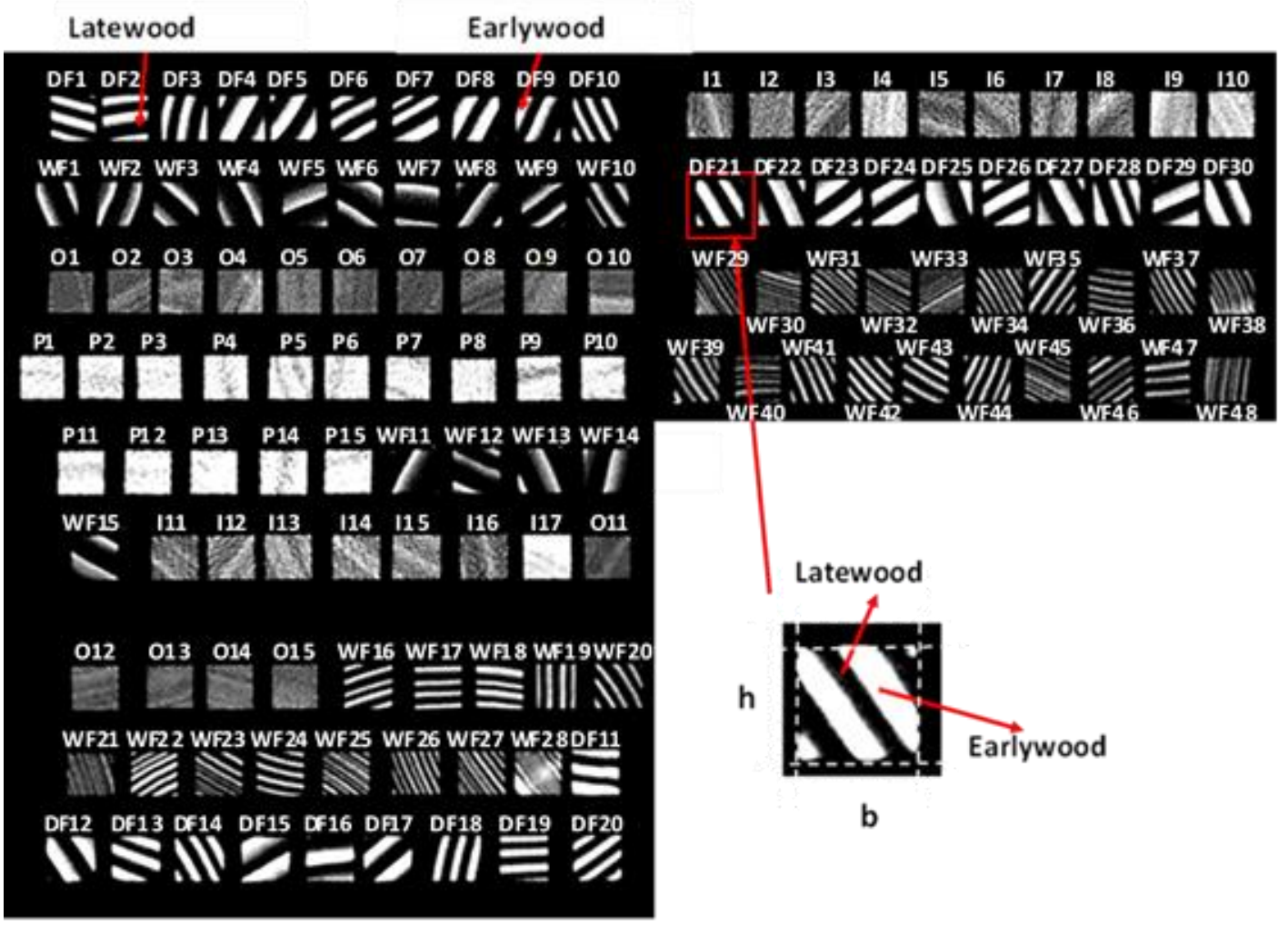

Fig. 5. Result from the CT-scanner with specimens named and numbered after species

Starting from this map (Fig. 5), Image $\mathrm{J}$ software was used to examine the width of the earlywood for the temperate specimens. The results and the summary of the width mean values of earlywood rings ( $\left.\varpi_{\text {mean }}\right)$ and the number mean values of earlywood rings $\left(N E_{\text {mean }}\right)$ are presented in Table 3. The tropical specimens had a lower $N E_{\text {mean }}$ than the temperate specimens. The lowest number of $N E_{\text {mean }}$ of 1.9 was in the case of P. For the tropical specimens, $\mathrm{O}$ had the highest $\mathrm{NE}_{\text {mean }}$ and $C O V$. The temperate specimens had the highest and lowest $C O V$ of $56.6 \%$ (WF) and $22.9 \%(\mathrm{DF})$, respectively, for the $N E_{\text {mean }}$. The $\varpi_{\text {mean }}$ could not be measured for the tropical specimens due to the difficulty of defining where earlywood starts and latewood ends (see Fig. 5 for specimens of species I, P, and O). A statistically significant difference could be seen between the $N E_{\text {mean }}$ of the grouped temperate and grouped tropical specimens. This difference occurs mainly due to the WF specimens which had a higher $N E_{\text {mean }}$ than other specimens.

Pambou Nziengui et al. (2020). "Annual growth rings," BioResources 15(2), 4282-4293. 4288 
Table 3. Mean Width (ळmean) and Number of Earlywood Rings ( $\mathrm{NE}_{\text {mean }}$ ) for the Groups of Tropical and Temperate Specimens with COV in Parentheses

\begin{tabular}{|l|c|c|c|}
\hline \multirow{3}{*}{ Temperate } & Name & $\varpi_{\text {mean }}(\mathrm{mm})$ & $N E_{\text {mean }}$ \\
\cline { 2 - 4 } & DF & $5.07(31.4 \%)$ & $2.8(22.9 \%)$ \\
\hline \multirow{3}{*}{ Tropical } & WF & $3.37(69.6 \%)$ & $5.5(56.6 \%)$ \\
\cline { 2 - 4 } & $\mathrm{I}$ & - & $2.3(29.9 \%)$ \\
\cline { 2 - 4 } & $\mathrm{P}$ & - & $1.9(30.7 \%)$ \\
\cline { 2 - 4 } & $\mathrm{O}$ & - & $2.5(45.6 \%)$ \\
\hline
\end{tabular}

\section{Assessment of the Annual Growth Ring in the Mechanical Properties of the Species Studied}

To understand the effects of the annual growth ring on the mechanical behavior, comparisons were made between the $\rho_{d r y}$ and NE (Fig. 6) and the $\rho_{d r y}$ and $\varpi$ (Fig. 7).
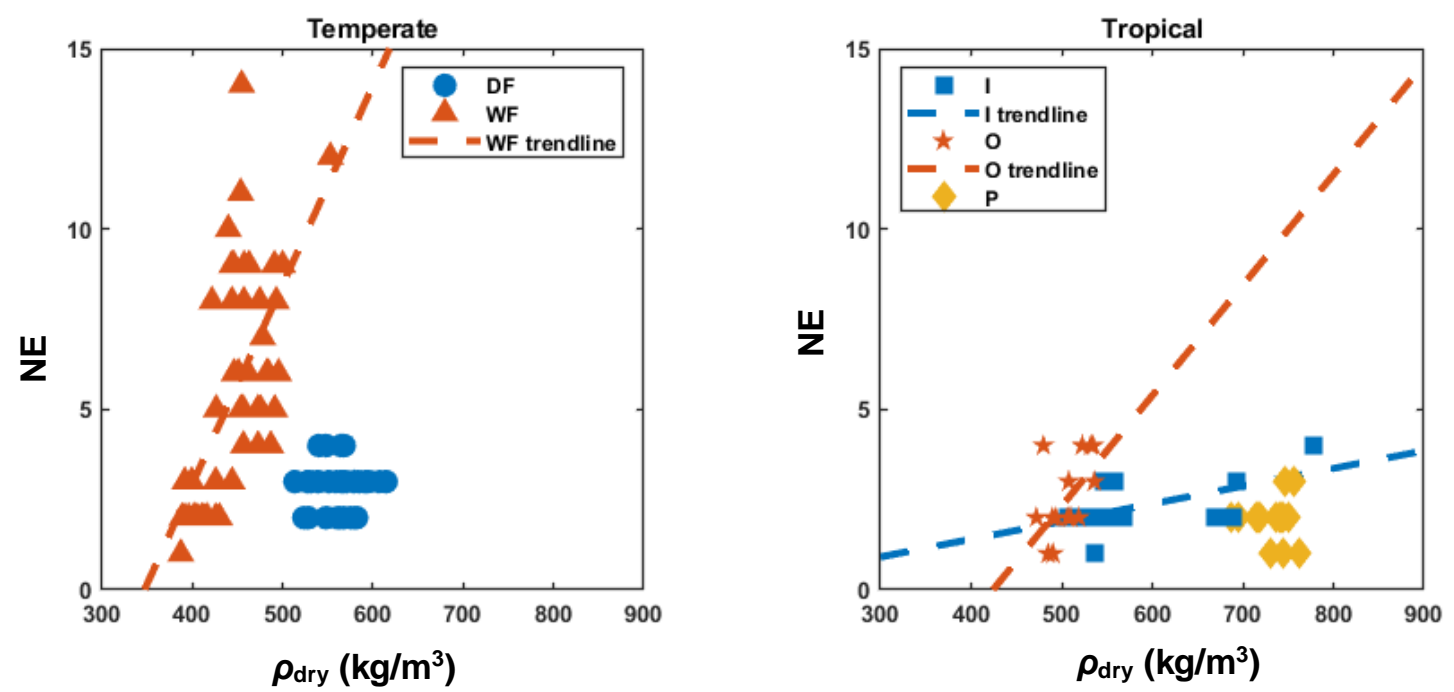

Fig. 6. Dry density $\left(\rho_{d r y}\right)$ versus the number of earlywood rings $(N E)$ for the groups of temperate and tropical specimens

The temperate specimens show that there was a correlation between the $\rho_{d r y}$ and $N E$. This conclusion was drawn only from the WF specimens and not the DF specimens due to the DF specimens low $C O V$ of $22.9 \%$. For the tropical specimens, a correlation between $\rho_{d r y}$ and $N E$ is difficult to see due to the low spread of the specimens. The illustrated trendlines for the tropical specimens had lower $\mathrm{R}^{2}$-values of 0.30 and 0.32 for I and $\mathrm{O}$, respectively, compared to the $\mathrm{R}^{2}$-value of 0.40 for WF. The tropical trendlines was showing a positive correlation between $\rho_{d r y}$ and $N E$ but due to the lower $\mathrm{R}^{2}$ values, the trend is not as clear as for the temperate specimens. For the group of DF specimens and the group of $\mathrm{P}$ specimens trendlines were not presented due to the low $\mathrm{R} 2$-values.

The correlation between the $\rho_{\text {dry }}$ versus $\varpi$ for the temperate specimens is presented in Fig. 7. A negative correlation between $\rho_{d r y}$ and $\varpi$ could be seen for the WF specimens. Due to the low COV of $22.9 \%$ and $31.4 \%$ for $\rho_{d r y}$ and $\varpi$, respectively, for the DF specimens it was not possible to see any correlation between $\rho_{d r y}$ and $\varpi$. The trendline for the group of WF specimens had an $\mathrm{R}^{2}$-value of 0.60. A trendline for the group of DF specimens was not presented due to the low $\mathrm{R}^{2}$-value. 


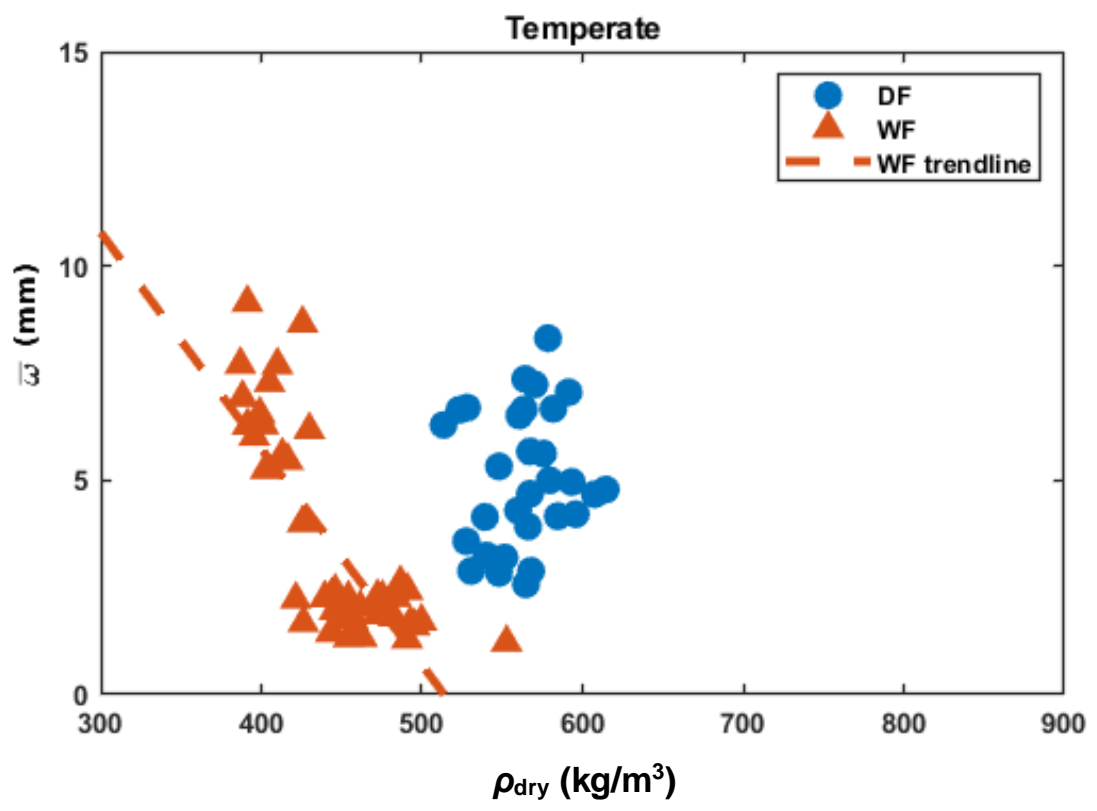

Fig. 7. Dry density $\left(\rho_{d r y}\right)$ versus the width of earlywood rings $(\varpi)$ for the groups of temperate specimens

\section{CONCLUSIONS}

1. An experimental study of the evaluation of the annual growth ring impact on the intrinsic physico-mechanical characteristics of wood was done. The samples were dimensioned and tested in a four-point flexural test according to the European standard requirement. Two groups of specimens were studied (temperate and tropical species). To be able to visualize the earlywood and latewood (annual growth ring), the specimens were scanned by a computed tomography scanner before the four-point flexural test. The results showed that, for temperate species, the distinction between earlywood and latewood is manifested in an annual growth ring and is easily distinguishable. However, for a tropical species the distinction is less clear. The study shows trendlines for the temperate and tropical specimens connecting the modulus of elasticity to the maximum flexural stress. It was also possible to show a trendline between the dry density and the maximum flexural stress for the two groups of temperate and tropical specimens of White fir and Iroko, respectively. Another trendline was shown between the dry density and number of earlywood rings for the group of temperate specimens of White fir and the groups of tropical specimens of Iroko and Okume. A last trendline was shown between the dry density and the mean width of the earlywood rings for the group of temperate specimens of White fir. The mean width of the earlywood rings was not possible to measure for the groups of tropical specimens due to the difficulty of define exactly where earlywood starts and latewood ends.

2. The results showed a connection between the annual growth rings of the tree and their intrinsic physico-mechanical characteristics mainly based on the dry density of the wood for both the tropical and temperate specimens. It was possible to show that the dry density was affected by the number and width of the earlywood rings. Moreover, the dry density affected the maximum flexural stress and where the maximum flexural stress is strongly connected to the modulus of elasticity. This results in an increased 
number of earlywood rings, which then results in an increased modulus of elasticity and increased maximum flexural stress.

3. These results illustrate the need to have a fairly large number of specimens to avoid the large variation noted within the mechanical properties determined in this work. These results are interesting but are limited by the fact that it is a new experimental approach used for this type of study. It could be necessary for the next experimental study to create a method to distinguish clearly the annual growth rings of tropical species by increasing, for example, the size of the samples to be studied.

\section{ACKNOWLEDGMENTS}

The authors would like to thank Luleå University of Technology in Skellefteå, Sweden, including the Wood Science and Engineering Division of the Department of Engineering and Mathematics for the provision of study materials and the support of this project. The authors also thank the TOR Program of the French Embassy in Sweden which allowed the initial collaboration but also the ANR for the financial support of this work through the project CLIMBOIS N ${ }^{\circ}$ ANR-13-JS09-0003-01 labeled ViaMeca. And finally, the authors thank the CNRS, which partly supported this work through the PEPS project "Green Engineering" RUMO and Region AURA thanks to SCUSI Project.

\section{REFERENCE CITED}

Abdelmohsen, S., Adriaenssens, S., El-Dabaa, R., Gabriele, S., Olivieri, L., and Teresi, L. (2019). "A multi-physics approach for modeling hygroscopic behavior in wood lowtech architectural adaptive systems," Computer-Aided Design 106, 43-53. DOI: 10.1016/j.cad.2018.07.005

Adamopoulos, S., Milios, E., Doganos, D., and Bistinas, I. (2009). "Ring width, latewood proportion and dry density in stems of Pinus brutia Ten.," European Journal of Wood and Wood Products 67(4), 471. DOI: 10.1007/s00107-009-0345-X

Bahar, R., Ouertani, S., Azzouz, S., Naili, H., El Ayeb, M. T., and El Cafci, A. (2019). "Mechanical properties changes in oak (Quercus canariensis) and stone pine (Pinus pinea) wood subjected to various convective drying conditions," European Journal of Environmental and Civil Engineering 1-13. DOI: 10.1080/19648189.2018.1500308

Brancheriau, L., Kouchade, C., and Brémaud, I. (2010). "Internal friction measurement of tropical species by various acoustic methods," J. Wood Sci. 56(5), 371-379.

EN 408:2010+A1 (2012). "Timber structures - Structural timber and glued laminated timber, Determination of some physical and mechanical properties" European Committee for Standardization, Brussels, Belgium.

Engonga Edzang, A. C., Pambou Nziengui, C. F., Ekomy Ango, S., Ikogou, S., and Moutou Pitti, R. (2020). "Comparative studies of three tropical wood species under compressive cyclic loading and moisture content changes," Wood Material Science \& Engineering 1-8. DOI : 10.1080/17480272.2020.1712739

Gérard, J., Guibal, D., Paradis, D., Vernay, M., Beauchêne, J., Brancheriau, L., Châlon, I., Daigremont, C., Détienne, P., Fouquet, D., Langbour, P., Lotte, S., Thévenon, MF., Méjean, C., and Thibaut, A. (2011). Tropix 7. CIRAD. DOI: 


\section{$10.18167 / 74726 f 706978$}

Gershon, A. L., Bruck, H. A., Xu, S., Sutton, M. A. and Tiwari, V. (2010). "Multiscale mechanical and structural characterizations of Palmetto wood for bio-inspired hierarchically structured polymer composites," Materials Science and Engineering C 30(2), 235-244. DOI: 10.1016/j.msec.2009.10.004

Jaskowska-Lemańska, J., and Wałach, D. (2016). "Impact of the direction of nondestructive test with respect to the annual growth rings of pine wood," Procedia Engineering 161, 925-930. DOI: 10.1016/j.proeng.2016.08.761

Manfoumbi Boussougou, N. (2012). Contribution à l'Adaptation de l'Eurocode 5 Aux Essences Tropicales Dans Leur Environnement, Thesis, Univ. Limoges, France.

Medzegue, M. J., Grelier, S., Bertrand, M., Nziengui, M., and Stokes, A. (2007). "Radial growth and characterization of juvenile and adult wood in plantation grown okoumé (Aucoumea klaineana Pierre) from Gabon," Annals of Forest Science 64(8), 815-824. DOI: 10.1051/forest:2007065

Miksic, A., Myntti, M., Koivisto, J., Salminen, L., and Alava, M. (2013). "Effect of fatigue and annual rings' orientation on mechanical properties of wood under crossgrain uniaxial compression," Wood Science and Technology 47(6), 1117-1133. DOI: 10.1007/s00226-013-0561-8

Mishnaevsky, L., and Qing, H. (2008). "Micromechanical modelling of mechanical behaviour and strength of wood: State-of-the-art review," Computational Materials Science 44(2), 363-370. DOI: 10.1016/j.commatsci.2008.03.043

Morales-Conde, M. J., and Machado, J. S. (2017). "Evaluation of cross-sectional variation of timber bending modulus of elasticity by stress waves," Construction and Building Materials 134, 617-625. DOI: 10.1016/j.conbuildmat.2016.12.188

Odounga, B., Pitti, R. M., Toussaint, E., and Grédiac, M. (2018). "Mode I fracture of tropical woods using grid method," Theoretical and Applied Fracture Mechanics 95, 1-17. DOI: 10.1016/j.tafmec.2018.02.006

Pambou Nziengui, C. F., Ikogou, S., and Moutou Pitti, R. (2018). "Impact of cyclic compressive loading and moisture content on the mechanical behavior of Aucoumea klaineana Pierre," Wood Material Science \& Engineering 13(4), 190-196. DOI: 10.1080/17480272.2017.1307281

Pambou Nziengui, C. F., Moutou Pitti, R., Fournely, E., Gril, J., Godi, G., and Ikogou, S. (2019). "Notched-beam creep of Douglas fir and white fir in outdoor conditions: Experimental study," Construction and Building Materials 196, 659-671. DOI: 10.1016/j.conbuildmat.2018.11.139

Ramage, M. H., Burridge, H., Busse-Wicher, M., Fereday, G., Reynolds, T., Shah, D. U., Wu, G., Yu, L., Fleming, P., Densley-Tingley, D., and Allwood, J. (2017). "The wood from the trees: The use of timber in construction," Renewable and Sustainable Energy Reviews 68, 333-359. DOI: 10.1016/j.rser.2016.09.107

Saavedra Flores, E. I., and Haldar, S. (2016). "Micro-macro mechanical relations in Palmetto wood by numerical homogenisation," Composite Structures 154, 1-10. DOI: 10.1016/j.compstruct.2016.06.050

Sopushynskyy, I., Kharyton, I., Teischinger, A., Mayevskyy, V., and Hrynyk, H. (2017). "Wood density and annual growth variability of Picea abies (L.) Karst. growing in the Ukrainian Carpathians," European Journal of Wood and Wood Products 75(3), 419-428. DOI: 10.1007/s00107-016-1079-1

Stanzl-Tschegg, S. E. (2006). "Microstructure and fracture mechanical response of wood," International Journal of Fracture 139(3-4), 495-508. DOI: 10.1007/s10704- 
006-0052-0

Timoshenko, P. S. (1968). Résistance des Matériaux. Dunod, Paris, https://cds.cern.ch/record/111473

Tran, T. B., Bastidas-Arteaga, E., Aoues, Y., Pambou Nziengui, C. F., Hamdi, S. E., Moutou Pitti, R., Fournely, E., Schoefs F., and Chateauneuf, A. (2018). "Reliability assessment and updating of notched timber components subjected to environmental and mechanical loading," Engineering Structures 166, 107-116. DOI: 10.1016/j.engstruct.2018.03.053

Treml, S., and Jeske, H. (2012). "Splinter formation of OSB strands during flat disc cutting of ring porous hardwoods," European Journal of Wood and Wood Products 70(1-3), 293-297. DOI: 10.1007/s00107-011-0559-6

Zeller, L., Ammer, C., Annighöfer, P., Biber, P., Marshall, J., Schütze, G., del Río Gaztelurrutia and Pretzsch, H. (2017). "Tree ring wood density of Scots pine and European beech lower in mixed-species stands compared with monocultures," Forest Ecology and Management 400, 363-374. DOI: 10.1016/j.foreco.2017.06.018

Article submitted: February 24, 2020; Peer review completed: April 3, 2020; Revised version received and accepted: April 16, 2020; Published: April 20, 2020.

DOI: 10.15376/biores.15.2.4282-4293 